\title{
ASO Author Reflections: Neoadjuvant Chemotherapy Switch: Optimizing Neoadjuvant Treatment Sequencing in Pancreas Cancer
}

\author{
Roberto Alva-Ruiz, MD (i), and Mark J. Truty, MD MS \\ Division of Hepatobiliary and Pancreas Surgery, Mayo Clinic, Rochester, MN
}

\section{PAST}

Neoadjuvant chemotherapy (NAC) is considered for patients with borderline resectable/locally advanced (BR/ LA) pancreatic adenocarcinoma (PDAC). A chemotherapeutic regimen that is both tolerable and demonstrably effective is of utmost importance as oncologic outcomes in these higher risk patients highly correlate with subsequent pathologic treatment responses. ${ }^{1}$ However, there are little data on the optimal treatment strategy in patients who do not objectively respond to or develop treatment-limiting toxicities with first-line (FL) NAC. ${ }^{2-4}$ In recent years, our center has adopted a 'chemotherapy switch' (CS) strategy for such patients. In our manuscript entitled 'Neoadjuvant Chemotherapy Switch in Borderline Resectable/Locally Advanced Pancreatic Cancer' we report on our cumulative high-volume institutional experience with CS, including frequency, indications, and outcomes of patients who require CS after initial FL NAC prior to curative-intent surgery. ${ }^{5}$

\section{PRESENT}

We were able to demonstrate that a substantial proportion $(30 \%)$ of patients required a chemotherapeutic switch after initial FL NAC due to the lack of objective treatment responses and/or chemotherapeutic toxicities. Of those undergoing CS, a majority were able to proceed to

(C) The Author(s) 2021

First Received: 18 October 2021

Accepted: 18 October 2021;

Published Online: 27 October 2021

M. J. Truty, MD MS

e-mail: truty.mark@mayo.edu curative-intent surgery after subsequent $\mathrm{CS}$. We found no major preoperative or perioperative differences between those undergoing resection after FL NAC compared with those who required CS. Importantly, there were no differences in pathologic or survival outcomes between cohorts, suggesting that such a CS strategy does not incur an oncologic detriment and can potentially be used to salvage those patients in whom FL chemotherapy is not tolerable or is ineffective. ${ }^{5}$

\section{FUTURE}

The presented results contribute to our overall understanding of appropriate neoadjuvant treatment sequencing and highlight the continued evolution of what constitutes an optimal treatment strategy for patients with anatomically borderline resectable or locally advanced PDAC. Based on these results, we suggest that CS be considered for all patients with initial suboptimal responses or in those who develop treatment-limiting toxicities to FL as a significantly important neoadjuvant strategy prior to consideration of surgical resection in order to improve outcomes for these patients. We anticipate the use of such a strategy combined with evolving NAC response metrics will improve the optimal selection of patients who could potentially benefit from curative-intent surgical resection.

\section{DECLARATIONS}

DISCLOSURES Roberto Alva-Ruiz and Mark J. Truty declare no conflicts of interest.

OPEN ACCESS This article is licensed under a Creative Commons Attribution 4.0 International License, which permits use, sharing, adaptation, distribution and reproduction in any medium or format, as long as you give appropriate credit to the original author(s) and the source, provide a link to the Creative Commons licence, and indicate 
if changes were made. The images or other third party material in this article are included in the article's Creative Commons licence, unless indicated otherwise in a credit line to the material. If material is not included in the article's Creative Commons licence and your intended use is not permitted by statutory regulation or exceeds the permitted use, you will need to obtain permission directly from the copyright holder. To view a copy of this licence, visit http://creativecommons. org/licenses/by/4.0/.

\section{REFERENCES}

1. Chun YS, Cooper HS, Cohen SJ, et al. Significance of pathologic response to preoperative therapy in pancreatic cancer. Ann Surg Oncol. 2011;18(13):3601-7. https://doi.org/10.1245/s10434-011-2 086-4.

2. Tempero MA, Malafa MP, Al-Hawary M, et al. NCCN guidelines version 2.2021. Pancreatic Adenocarcinoma. 2021. https://www. nccn.org/professionals/physician_gls/pdf/pancreatic.pdf. Accessed 13 May 2021.
3. Hahn S, Ayav A, Lopez A. Resection of locally advanced pancreatic neoplasms after neoadjuvant chemotherapy with nabpaclitaxel and gemcitabine following FOLFIRINOX failure. Case Rep Gastroenterol. 2017;11(2):422-7. https://doi.org/10.1159/ 000478722.

4. Vreeland TJ, McAllister F, Javadi S, et al. Benefit of gemcitabine/ nab-paclitaxel rescue of patients with borderline resectable or locally advanced pancreatic adenocarcinoma after early failure of FOLFIRINOX. Pancreas. 2019;48(6):837-43. https://doi.org/10.1 097/MPA.0000000000001345.

5. Alva-Ruiz R, Yohanathan L, Yonkus JA, et al. Neoadjuvant chemotherapy switch in borderline resectable/locally advanced pancreatic cancer. Ann Surg Oncol. 2021. https://doi.org/10.1245/ s10434-021-10991-2.

Publisher's Note Springer Nature remains neutral with regard to jurisdictional claims in published maps and institutional affiliations. 